\title{
Microbial metabolism of chlorosalicylates: effect of prolonged subcultivation on constructed strains
}

\author{
Miguel Angel Rubio ${ }^{1}$, Karl-Heinrich Engesser ${ }^{2}$, and Hans-Joachim Knackmuss ${ }^{3}$ \\ 1 Technische Universität Hamburg-Harburg, Abt. für Gewässerreinigungstechnik, D-2100 Hamburg 90, Federal Republic of Germany \\ ${ }^{2}$ Lehrstuhl für Chemische Mikrobiologie der Bergischen Universität, Gesamthochschule Wuppertal, \\ D-5600 Wuppertal 1, Federal Republic of Germany \\ ${ }^{3}$ Institut für Mikrobiologie der Universität Stuttgart, D-7000 Stuttgart 1, Federal Republic of Germany
}

\begin{abstract}
The hybrid strain Pseudomonas sp. WR4016 was subcultivated with increasing concentrations of 5-chlorosalicylate $(5 \rightarrow 10 \mathrm{mM})$ as sole carbon source over a period of 9 months. At intervals of approximately 3 months derivative strains WR4017, WR4018 and WR4019 were isolated which exhibited higher growth rates and increased substrate tolerance. Comparative analysis of the turnover rates of the key enzymes in chlorosalicylate degradation showed that the adaptation process did not result from structural modifications of these proteins. Instead, balanced overproduction of the salicylate hydroxylase and catechol 1,2-dioxygenase prevented the accumulation of toxic chlorocatechols and accounted for the reduction of the doubling times with 4- or 5-chlorosalicylate. A comparative analysis of a genetically engineered chlorosalicylate degrader PL3001 showed similar regulatory patterns as the most advanced isolate WR4019 from the adaptation series.
\end{abstract}

Key words: Balanced regulations - Higher growth rates Cloned strain PL300-1 - Pseudomonas

In the course of evolution the development of enzymes to higher catabolic rates for critical reactions in a degradation pathway has permitted microbial utilization of otherwise refractory substrates. Although some compounds occurring in nature are known to be resistent to bacterial attack (US Environmental Protection Agency 1979) most recalcitrant substances with a strong xenobiotic character are man made (Alexander 1975). Many of these contain one or more halogen atoms which strongly inhibit bacterial growth (Reineke 1984). This may occur in industrial sewage treatment plants with incoming waste waters containing loads of such xenobiotics (Knackmuss 1983).

Several studies have shown that complete microbial utilization of some haloaromatics can be performed by organisms existing in nature (Chatterjee et al. 1981; Evans et al. $1971 \mathrm{a}, \mathrm{b}$; Crawford et al. 1979). Other haloarenes degrading bacteria have been isolated from mixed cultures by prolonged adaptation in chemostats under high selective pressures (Dorn et al. 1974; Hartmann et al. 1979). The in vivo or in vitro construction of such bacteria was also reported (Latorre et al. 1984; Reineke and Knackmuss 1979 , 1984; Reineke et al. 1982; Schwien and Schmidt 1982). In this case the degradation of haloaromatics was achieved by

Offprint requests to: $\mathrm{H}$.-J. Knackmuss combining preexisting haloarenes cometabolizing activities with chlorocatechols dissimilating sequences. This "recruitment" of catabolic functions from different organisms in a constructed strain is frequently accompanied by regulatory problems. The accumulation of toxic intermediates can prevent growth or cause prolonged generation times with novel substrates (Engesser et al. 1980). In the case of chlorosalicylates the accumulation of the product of salicylatehydroxylase, chlorocatechol, has to be prevented by proper regulation of specific activities of both enzymes. Otherwise chlorocatechols would accumulate causing death of the microbial population (Schreiber et al. 1980). In methylsalicylates degrading Pseudomonas sp. WR401, the parent strain of the constructed series of hybrids WR4016 to WR4019 (see accompanying paper), specific activities of the salicylate hydroxylation reaction are always considerably lower than the activity of the cleavage enzymes of catechols.

In this paper we present evidence, that this balance of induced enzyme levels is maintained during the evolution of WR4016 to higher growth rates with 5-chlorosalicylate. We attempt to explain the reason for this improvement and finally compare the best isolate of this series, WR4019 with a in vitro constructed chlorosalicylate degrader PL300-1. This strain was obtained by transfering cloned genes of the NAH-plasmid into Pseudomonas sp. B13 (Lehrbach et al. 1984).

\section{Materials and methods}

Organisms. The in vitro constructed chlorosalicylate degrader Pseudomonas sp. PL300-1 was described previously (Lehrbach et al. 1984). Pseudomonas sp. WR4016, its culture conditions, enzyme assays, all analytical methods and chemicals used have been described in the accompanying paper (Rubio et al. 1986).

\section{Results and discussion}

The 4- and 5-chlorosalicylate degrading hybrid strain Pseudomonas sp. WR4016 was subcultivated for several months with increasing concentrations $(5-10 \mathrm{mM})$ of 5-chlorosalicylate (5CS). After 3,6 and 9 months derivative strains, WR4017, WR4018 and WR4019 with considerably improved degradative performance towards chlorosalicylates were isolated. With respect to the degradative ability the improved strains WR4017, WR4018 and WR4019 maintained the same phenotype as the parent organism 
Table 1. Relative rates of oxygen uptake at the expense of salicylate methylsubstituted and halosubstituted salicylates by whole cells of strains WR4016, WR4017, WR4018 and WR4019 grown with 5-chlorosalicylate

\begin{tabular}{lcccc}
\hline Assay substrate & \multicolumn{3}{l}{$\begin{array}{l}\text { Relative rates of oxygen uptake } \\
\text { with cells of }\end{array}$} \\
\cline { 2 - 5 } & WR4016 & WR4017 & WR4018 & WR4019 \\
\hline Salicylate & $100(12)$ & $100(17)$ & $100(21)$ & $100(26)$ \\
3-Methylsalicylate & 44 & 38 & 32 & 38 \\
4-Methylsalicylate & 55 & 50 & 50 & 47 \\
5-Methylsalicylate & 32 & 34 & 31 & 31 \\
3-Chlorosalicylate & 13 & 11 & 11 & 11 \\
4-Chlorosalicylate & 65 & 70 & 80 & 87 \\
5-Chlorosalicylate & 60 & 70 & 69 & 64 \\
5-Fluorosalicylate & 52 & 42 & 46 & 52 \\
5-Bromosalicylate & 57 & 44 & 44 & 58 \\
\hline
\end{tabular}

a The oxygen uptake rates are expressed as percentages of that for salicylate $(100 \%)$. The specific activities, given in micromol $\mathrm{O}_{2}$ per min per $\mathrm{g}$ protein, appear in parentheses

WR4016. Thus, all isolates could utilize 4-chlorosalicylate (4CS) and 5CS but not 3-chlorosalicylate (3CS) as sole carbon source. The new isolates showed, however, increasingly higher growth rates with both substrates. Accordingly, WR4017, WR4018 and WR4019 grew on 4CS with $t_{\mathrm{d}}=12 \mathrm{~h}, 10 \mathrm{~h}$ and $7 \mathrm{~h}$ respectively. Similarly, with $5 \mathrm{CS}$ doubling times were $13 \mathrm{~h}, 9,5 \mathrm{~h}$ and $5,5 \mathrm{~h}$ respectively. With respect to $5 \mathrm{CS}$ as growth substrate the performance of WR 4019 was similar to that of the in vitro constructed strain PL-300-1 (Lehrbach et al. 1984). Both organisms had $t_{\mathrm{d}}=5,5 \mathrm{~h}$ on that substrate. With $4 \mathrm{CS}$ however, strain PL300-1 exhibited a considerably longer doubling time $\left(t_{\mathrm{d}}=11,5 \mathrm{~h}\right)$ compared to WR4019 $\left(t_{\mathrm{d}}=7 \mathrm{~h}\right)$. Furthermore, the strains from prolonged subcultivation tolerated increasing concentrations of chlorosalicylates. At low cell densities $\left(\mathrm{OD}_{546}=0.1\right)$ the original strain WR4016 was quite sensitive towards substrate concentrations $\geq 5 \mathrm{mM}$ so that relative high cell densities $(O D \geq 0.25)$ were necessary for initiating growth with $5 \mathrm{CS}$.

In contrast, strain WR4017 was not inhibited at concentrations of $\leq 7 \mathrm{mM}$ (initial $\mathrm{OD}_{546}=0.1$ ). The strains WR4018 and WR4019 showed the highest tolerance towards chlorosalicylates. They grew uninhibited at a conc. of $10 \mathrm{mM}$ (strain PL-300-1 grew only with difficulty at conc. above $6 \mathrm{mM}$ ). The optical density reached with this substrate
Table 2. Comparison of oxygen uptake rates of whole cells of Pseudomonas sp. PL300-1, WR4016, WR4017, WR4018 and WR4019 with 5CS and 4-chlorocatechol

\begin{tabular}{llllll}
\hline $\begin{array}{l}\text { Assay } \\
\text { substrate }\end{array}$ & \multicolumn{4}{l}{$\begin{array}{l}\text { Oxygen uptake with whole cells } \\
\text { of 5-chlorosalicylate grown Pseudomonas sp. }\end{array}$} \\
\cline { 2 - 6 } & PL300-1 & WR4016 & WR4017 & WR4018 & WR4019 \\
\hline $\begin{array}{c}\text { Salicylate } \\
\text { 5-Chloro- }\end{array}$ & 23 & 12 & 17 & 21 & 26 \\
$\begin{array}{c}\text { salicylate } \\
\text { 4-Chloro- } \\
\text { catechol }\end{array}$ & 15 & 8 & 12 & 15 & 17 \\
\hline
\end{tabular}

The specific activities of oxygen uptake are given in micromol $\mathrm{O}_{2}$ per min per $\mathrm{g}$ protein

concentration was approx. 1.0 with all isolates irrespective of whether $4 \mathrm{CS}$ or $5 \mathrm{CS}$ had been used as growth substrate. At all times and for all strains tested doubling of the optical density corresponded to a proportional increase of the chloride concentration in the culture medium.

In order to account for the higher growth rates and increasing tolerance of the isolates towards chlorosalicylates the relative and specific activities of two key enzymes of the degradation pathway were compared. Judging by the relative turnover rates of the salicylate hydroxylase with various substituted salicylates no significant change of the specificity of this enzyme had taken place in any of the isolates (Table 1). However, during adaptation to increasing concentrations of $5 \mathrm{CS}$ isolates were obtained with higher levels of enzyme activities of the unmodified salicylate hydroxylase. By comparing the specific $\mathrm{O}_{2}$ uptake rates for chlorosalicylates with those for chlorocatechols it became clear that the salicylate hydroxylase catalysed reaction represents the rate determining step of the degradative sequence (Table 2). Obviously, since the oxygen uptake rates comprise the activities of two oxygenases (salicylate hydroxylase and catechol dioxygenase) the hydroxylation of salicylates is always slower than the ring cleavage reaction and therefore rate limiting. Consequently, for each isolate the observed increase in specific activities of the salicylate hydroxylase is proportional to the increase in growth rates with $4 \mathrm{CS}$ or $5 \mathrm{CS}$. Noticeably, the higher turnover rates for halosalicylates did not result in an accumulation of toxic halocatechols. In fact, during growth with chlorosalicylates we never observed any accumulation of chlorocatechols resulting in

Table 3, Relative and specific activities of catabolic enzymes in cell extracts of strain WR4016, WR4017, WR4018, WR4019 grown on 5-chlorosalicylate ${ }^{\text {a }}$

\begin{tabular}{|c|c|c|c|c|c|}
\hline \multirow[t]{2}{*}{ Enzyme activity } & \multirow[t]{2}{*}{ Assay substrate } & \multicolumn{4}{|c|}{ sp. act. (U/g protein) } \\
\hline & & WR4016 & WR4017 & WR4018 & WR4019 \\
\hline Catechol-1,2-dioxygenase & $\begin{array}{l}\text { Catechol } \\
\text { 3-Chlorocatechol }\end{array}$ & $\begin{array}{l}74(100) \\
98(132)\end{array}$ & $\begin{array}{r}121(100) \\
(107)\end{array}$ & $\begin{array}{r}170(100) \\
(107)\end{array}$ & $\begin{array}{r}250(100) \\
(123)\end{array}$ \\
\hline Cis,cis-muconic acid cycloisomerase & 2-Chloro-cis,cis-muconic acid & 60 & 60 & 60 & 80 \\
\hline $\begin{array}{l}\text { 4-Carboxymethylenebut-2-en- } \\
\text { 4-olide hydrolase }\end{array}$ & $\begin{array}{l}\text { trans-4-Carboxymethylencbut- } \\
\text { 2-en-4-olide }\end{array}$ & 900 & 1100 & 1200 & 1500 \\
\hline
\end{tabular}

- Cells were harvested during exponential growth. Enzyme activities were determined as described in an accompanying publication. The values in parentheses represent relative activities (catechol $=100 \%$ ) 
a pink to brown coloration of the growth medium. Compared to the precursor strain WR4016 all of the isolates exhibit higher specific activities of catechol 1,2-dioxygenase (Table 2). Thus, an increase in specific activity was accompanied by a concomitant increase in the induction level of the halocatechol cleaving enzyme. This phenomenon permitted a faster conversion of halosalicylates and a rapid detoxification of lethal metabolites. A similar induction pattern prevented accumulation of toxic chlorocatechols during growth of the in vitro constructed strain PL300-1 with chlorosalicylates (Table 2).

In contrast to the drastic increase of the catechol 1,2dioxygenase levels, the specific activities of the other enzymes of chlorocatechol assimilation were only slightly elevated (Table 3 ). There seems to be no substantial overproduction of cycloisomerase and hydrolase indicating that these two enzymes are regulated differently from the ring cleaving activity. The data presented in this study provide evidence that prolonged subcultivation under high selective pressures improved the performance of primary hybrids such as WR4016 substantially. The fastest growing strain of the evolution series, WR4019, showed a substantial increase in the degradation rates of 4CS and 5CS. This improved performance was due to the overproduction of two key enzymes, salicylate hydroxylase and the catechol 1,2dioxygenase. We showed that the stepwise increase of the level of these, probably independently regulated, enzymes was balanced appropriately in order to avoid accumulation of toxic chlorocatechols (Knackmuss 1984). These balanced induction is essential for successful recruitment of foreign genes within a new host. This has also been demonstrated in chloroaniline degrading bacteria (Latorre et al. 1984). The development of chlorosalicylate degrading strains was achieved in vivo as well as in vitro. Whereas the former requires only a very simple technique, extensive knowledge of the biochemistry and genetics of the pathway to be cloned is necessary in the latter case.

Acknowledgements. We wish to thank the Federal Ministry for Research and Technology (Bundesministerium für Forschung und Technologie) for supporting this investigation. We wish to thank Prof. Dr. Walter Reineke for helpful discussions during this investigation.

\section{References}

Alexander M (1975) Environmental and microbiological problems arising from recalcitrant molecules. Microb Ecol 2:17-27

Chatterjee DK, Kellog TS, Hamada S, Chakrabarty AM (1981) Plasmid specifying total degradation of 3-chlorobenzoate by a modified ortho-pathway. J Bacteriol 146:639-646

Crawford RL, Olson PE, Frick TD (1979) Catabolism of 5-chlorosalicylic acid by a bacillus isolated from the Mississippi River. Appl Environ Microbiol 38:379-384
Dorn E, Hellwig M, Reineke W, Knackmuss HJ (1974) Isolation and characterization of a 3-chlorobenzoate degrading Pseudomonad. Arch Microbiol 99:61 - 70

Engesser KH, Schmidt E, Knackmuss HJ (1980) Adaptation of Alcaligenes eutrophus B9 and Pseudomonas sp. B13 to 2-fluorobenzoate as growth substrate. Appl Environ Microbiol 39: $68-73$

Evans WC, Smith BS, Fernley HN, Davies JI (1971a) Bacterial metabolism of 2,4-dichlorophenoxyacetate. Biochem J 122: $543-551$

Evans WC, Smith BS, Moos P, Fernley HN (1971 b) Bacterial metabolism of 4-chlorophenoxyacetate. Biochem J 122: $509-517$

Hartmann J, Reineke W, Knackmuss HJ (1979) Metabolism of 3-chloro-, 4-chloro- and 3,5-dichlorobenzoate by a pseudomonad. Appl Environ Microbiol 37:421-428

Knackmuss HJ (1983) Xenobiotic degradation in industrial sewage: haloaromatics as target substrates. Biochem Soc Symp 48: $173-190$

Knackmuss HJ (1984) Biochemistry and practical implications of organohalide degradation. In: Klug MJ, Reddy CA (eds) Current perspectives in microbiol ecology. ASM, Washington, pp 687-693

Latorre J, Reineke W, Knackmuss HJ (1984) Microbial metabolism of chloroanilines: enhanced evolution by natural genetic exchange. Arch Microbiol 140:159-165

Lehrbach PR, Zeyer J, Reineke W, Knackmuss HJ, Timmis KN (1984) Enzyme recruitment in vitro: use of cloned genes to extend the range of haloaromatics degraded by Pseudomonas sp. strain B13. J Bacteriol 158:1025-1032

Reineke W (1984) Microbial degradation of halogenated aromatic compounds. In: Gibson DT (ed) Microbial degradation of organic compounds. Marcel Dekker, Basel, pp 319-360

Reineke W, Knackmuss HJ (1979) Construction of haloaromatics utilizing bacteria. Nature $277: 385-386$

Reineke W, Knackmuss HJ (1984) Microbial metabolism of haloaromatics. Isolation and properties of a chlorobenzene degrading bacterium. Appl Environ Microbiol 47:395-402

Reineke W, Wessels SW, Rubio MA, Latorre J, Schwien W, Schmidt E, Schlömann M, Knackmuss HJ (1982) Degradation of monochlorinated aromatics following transfer of genes encoding chlorocatechol catabolism. FEMS Microbiol Lett $14: 291-294$

Rubio MA, Engesser KH, Knackmuss HJ (1986) Microbial metabolism of chlorosalicylates: accelerated evolution by natural genetic exchange. Arch Microbiol 145:116-122

Schreiber A, Hellwig M, Dorn E, Reinckc W, Knackmuss HJ (1980) Critical reactions in fluorobenzoic acid degradation by Pseudomonas sp. B13. Appl Environ Microbiol 39:58-67

Schwien J, Schmidt E (1982) Improved degradation of monochlorophenols by a constructed strain. Appl Environ Microbiol $44: 33-39$

US Environmental Protection Agency (1979) Polycyclic aromatic hydrocarbons. In: Water-related environmental fate of 129 priority pollutants, vol II. EPA-440/4-79-0296. Washington DC

Received October 25, 1985/Accepted March 25, 1986 